\title{
Klinik Uygulama Rehberleri
}

\author{
Rabia Şebnem Yakışan ${ }^{1}$, Turan Set ${ }^{2}$
}

${ }^{1}$ Arş.Gör., ${ }^{2}$ Doç.Dr. Atatürk Üniversitesi Tıp Fakültesi Aile Hekimliği Anabilim Dalı

\section{ÖZET}

Sağlık uygulamalarının kalitesinin artırılması, hataların azaltılması, bakım maliyetinin azalması ve bakımın standardize edilmesi için klinik uygulama rehberleri geliştirilmiştir. Bu yazıda klinik uygulama rehberlerinin tanımı, hazırlanışı ve yararları anlatılmıştır.

Anahtar kelimeler: Klinik uygulama rehberleri, kanıta dayalı tıp

\section{ABSTRACT}

Clinical practice guidelines have been developed to increase the quality of health care, to reduce mistakes and costs, and to standardize the health care. The definition, preparation and benefits of the clinical practice guidelines are discussed in this article.

Key words: Clinical practice guidelines, evidence based medicine

Yakışan RŞ, Set T. Klinik Uygulama Rehberleri. TJFMPC 2013;7(2):26-28

\section{Giriş}

Hekimlik uygulamaları çok geniş bir yelpazeye sahip olup, pek çok durumda farklı uygulamalarla karşılaşılabilinmektedir. Günümüzde uygulamalardaki bu farklılıkların azaltılması, tıbbi hataların azaltılması, bakımın standardize edilmesi ve sağlık hizmet kalitesinin artırılması için kanıta dayalı tıp uygulamalarının önemi giderek artmaktadır.

Kanıta dayalı uygulama, klinik kararları desteklemek için elde edilebilen en iyi kanıtların kullanılma sürecidir ${ }^{1}$. Sağlık hizmetlerinde, kanıta dayalı uygulama, belli bir konuda araştırma sonuçlarının seçilmesi, sonuçların sentezlenmesi ve bu sonuçların klinik uygulama kararları için hazırlanmasıdır 2. Araştırma ile uygulama arasındaki uçurumu kapatmayı amaçlar. Kanıta dayalı tıp ilkelerinin tüm sağlık disiplinlerinde uygulanması "Kanıta Dayalı Sağlık Bakımı" olarak da tanımlanmaktadır. Bu hareketin hızlanmasında, sağlık sistemleri ve profesyonel örgütlerin taleplerinin yanı sıra tıbbi uygulama hatalarındaki artış da belirleyici olmuştur ${ }^{3}$. Sağlık bakım uygulamalarının kanıta dayandırılması gereklilikleri olarak "bakım maliyetinde artış, bakımın sadece $\% 20$ sinin kanıta dayalı olması, hastaların hatalı

\footnotetext{
Iletişim adresi:

Turan Set

Atatürk Üniversitesi Tıp Fakültesi

Aile Hekimliği Anabilim Dalı,

25240, Yakutiye/Erzurum

Tel: 04422312528

E-mail: turanset@gmail.com

Geliş Tarihi: 05.01.2012

Kabul Tarihi: 06.03.2013
}

uygulama kaygısı, hastaların bilgi taleplerinde artış ve sağlık personeline güvenin azalması" konularına dikkat çekilmektedir.

Tıptaki bu gelişmeler ve bilgi yoğunluğunun çok fazla artması sonucunda kanıta dayalı uygulamalar çerçevesinde ilgili sürecin yönetilmesi için çeşitli rehberler geliştirilmiştir. Bu yazıda tıpta uygulama rehberinin tanımı, yararları ve hazırlanması hakkında bilgi verilmesi amaçlanmıştır.

\section{Tanım}

Klinik uygulama rehberleri, özel koşullarda hekimlere hastayla ilgili kararlarında yardımcı olmak üzere tasarlanmıs sistematik açıklamalardır 4,5 . Rehberler uygulanması zorunlu protokoller değildir. Rehberlerin rolü iki faktör varlığında açıktır: 1) Hasta sonuçlarını etkileyen uygulama çeşitliliği, 2) Etkili uygulama için güçlü verilere dayalı araştırma tabanı varlığı ${ }^{6}$. Rehberler, diğer klinik uygulamalardan izole olarak görülmemelidir. Rehber gelişimi, uygulanması ve değerlendirilmesi bir halkanın birbirine bağımlı aktiviteleridir. Bunlar; araştırmaları pratiğe dönüştürmek, standartların belirlenmesi ve izlemi ile herhangi bir serviste klinik mükemmelliği sağlamak gibi bir dizi tamamlayıcı etkinliğin parçasıdır. Rehberler katkıda bulunur, ancak mükemmel hasta sonuçları sağlamayı ve geliştirmeyi garanti etmek için yeterli değildir ${ }^{6}$. Karar aşamasında hasta katılımını da sağlamalıdır.

\section{Rehberler nasıl oluşturulur?}

Rehberlerin oluşturulması zaman, emek ve ekip çalışması gerektirir. Uygulama rehberlerinin oluşturulmasında sistematik olarak uyulması gereken aşamalar vardır (Tablo 1). 
Klinik uygulama rehberleri oldukça faydalı kılavuzlar olmakla birlikte oluşturulmasında ve uygulamada bazı zorluklarla karşılaşılabilmektedir ${ }^{7-}$ 10

Tablo 1. Klinik uygulama rehberlerinin hazırlanma basamakları $^{6}$

\section{Rehber konusunun seçimi}

Bir kılavuz geliştirme grubu oluşturulması: Konu ile ilgili her gruptan temsilci olmalıdır. İdari sorumlu, sponsor, proje yöneticisi, araştırmacı, eczacı, hasta, etik inceleme kurulu ve ilgili branşın uzmanları bulunmalıdır.

\section{Sistematik literatür taranması \\ Önerilerin oluşturulması}

Danışma ve kanıtların değerlendirilmesi: Elde edilen veriler dikkatli bir şekilde gözden geçirilmeli, en yüksek kaliteli kanıta dayanan veriler dikkate alınmalıdır.

Yayın ve yaygınlaştırma: Öncelikle kullanıcılara sunulmalı ve geri bildirimlere göre son hali verilerek yayınlanmalıdır.

Uygulama: $\mathrm{Bu}$ dönemde yoğun bir eğitim verilmelidir. Rehberlere erişim kolaylaştırılmalıdır. Gözden geçirme: Her yıl klinik, ekonomik ve hasta tabanlı sonuçlar değerlendirilmeli ve gerekli değişiklikler yapılmalıdır.

\section{Rehber oluşturulmasındaki sorunlar}

Rehberlerin hazırlanmasında çeşitli sınırlamalar vardır. Kaynakların miktarı ve tutarlılığı, çalışma bulgularının genellenebilirliği ve uygulanabilirliği önemlidir. Öncelikle dayandığı kanıtların iyi olması gerekir. Maalesef bilim her zaman klinik bakımdaki sorulara açık cevaplar sağlayamaz. Buna ek olarak rehberleri desteklemek için kullanılan çalışmalar kötü tasarlanmış veya sınırlı uygulamalara sahip olabilir. Bu faktörler kanıta dayalı yaklaşımın rehber hazırlanmasında önemli olduğunu göstermektedir. Bu nedenle rehberler yeni bilimsel gelişmeler ve teknolojilere ayak uydurarak güncellenmelidir ${ }^{11}$.

\section{Uygulama rehberlerinin yararları}

Kılavuzlar, sağlık bakımının kalitesini artırmak ve objektif medikal kararlar alabilmek için hekimler tarafından tasarlanmıştır. Böylece kaynaklar etkili bir biçimde kullanılarak sağlık harcamaları azaltılabilir (4). Hastaların uygun maliyetli kanıta dayalı bakıma erişebilmeleri sağlanır. Dünyanın birçok bölgesinde, kaynak yoksunluğu nedeniyle bakımın belirli standartlarının uygulanmasının sınırlı kaldığı bilinmektedir. Rehberler, kaynakların önemli ölçüde farklılık gösterdiği ortamlarda uygun maliyetli, kanıta dayalı bakım uygulamasını geliştirmeye yönelik pratik bir yaklaşım sağlamaktadır ${ }^{12}$.

Birçok çalışmada uygulama rehberlerinin klinik uygulamaları geliştirdiği vurgulanmıştır. Rehberler klinikte hasta yaklaşımı için bir temel oluşturur ${ }^{13,14}$. Kalite ve kullanım yöntemleri için değerlendirme ölçütü sağlar ${ }^{15}$.

Rehberler klinik belirsizliklerin azaltılması, daha iyi hizmet verilmesi ve zaman kazanılması açısından önemlidir. Örneğin; birinci basamakta menenjit şüpheli bir vaka ile karşılaştık. Rehbere göre ${ }^{16}$; akut başlangıçlı ateş (rektal $\geq 38,5^{\circ} \mathrm{C}$ veya aksiller $\geq 38^{\circ} \mathrm{C}$ ) ile birlikte ense sertliği ve/veya bilinç değişikliği ve/veya diğer meningeal irritasyon bulgularının varlığı ve/veya peteşiyal ya da purpural döküntü ile karakterize hastalık tablosu ile karşılaşıldığında meningokoksik menenjitten şüphelenilmelidir. Rehber, bu durumu "olası vaka" olarak açıklamaktadır. Böyle bir vaka ile karşılaşıldığında rehbere göre ileri tetkik ve yatarak tedavi amacıyla üst basamağa yönlendirilmesi gerekmektedir. Bu durumda hasta menenjit ön tanısı ile bir üst basamağa sevk edilmelidir. Bu vakada kan kültürü yapılması, lökosit sayımı veya daha ileri tetkiklerin yapılması, hastanın sevk kararını değiştirmeyeceği gibi zaman kaybına ve gereksiz sağlık harcamalarına neden olacaktır.

Bununla birlikte rehberler yaptırım olarak değil, klinik kararlara yardımcı olarak görülmelidir. Rehberlere uyum yüzde yüz mümkün olmayabilir, klinik durum rehbere uymamak için geçerli bir neden teşkil ediyor olabilir. Bunlar hastayla ilgili komorbid durumlar, yaş ve diğer komplike durumlar olabilir. Hasta sonuçları kaliteyi yansıttığı gibi profesyonel sorumluluğun katı bir temeli olmamalıdır. Uygulama rehberleri klinik kararlara yardımcı olarak görülmelidir. Düzgün ve yerinde kullanılmadığında faydasızdır.

\section{Aile Hekimliği Klinisyenliği Bağlamında Uygulama Rehberlerinin Önemi}

Aile hekimleri yaş, cinsiyet ve rahatsızlık ayrımı yapmaksızın tıbbi bakım arayan her bireye kapsamlı ve sürekli bakım vermekle sorumlu kişisel doktorlardır. Sağlığın korunması ve geliştirilmesi, rehabilitasyon ve tedavi ile ilgili sağlık hizmetlerini bir bütün olarak sunmaktadır. Bütün bunlar göz önüne alındığında aile hekiminin sınırlı bir nüfusa sağlık hizmeti vermesine rağmen hizmet kapsamı oldukça geniştir. Sağlık hizmetlerinin çeşitliliği nedeniyle, kanıta dayalı ve doğru klinik uygulamaların gerçekleştirilmesi için karşılaşılabilecek tıbbi durumlarla ilgili daha fazla kaynağa ihtiyaç duyulacaktır. Bu nedenlerden dolayı uygulama rehberlerinin kanıta dayalı klinik uygulamalarda ve standartların korunmasında 
hekime yardımcı olması açısından, diğer uzmanlık alanlarına göre aile hekimleri için ayrıca önemli olduğu söylenebilir.

\section{Uygulamada yaşanan sorunlar}

Sağlık profesyonelleri rehberin dayandığı kaynağı önemsemektedir. Çünkü hasta sonuçlarına olumlu etkisi olan bir hasta yönetimi sergilediklerinden emin olmak istemektedirler. Başka bir deyişle belirli bir rehberin hastaları için doğru olduğunu ve çalıştıkları sistemin rehberin uygulanması için uygun olduğunu bilmeye intiyaçları vardır. Rehberin düzgün uygulanabilmesi için yeterli zaman, ekipman, donanımlı personel, bölümler arası koordinasyon olması gerekmektedir.

Rehberlerin yalnızca gelişimi ve benimsenmesi yeterli değil, hasta sonuçlarındaki olumlu katkıları da değerlendirilmelidir. Rehberler özenle araştırılabilir ve titiz bir şekilde hazırlanabilir, ama günlük klinik uygulamalara dâhil olmaya uygun değilse, hasta sonuçlarında farklılığa yol açar böylece geliştirmek için olan çabalar boşa gider ${ }^{11}$.

\section{Sonuç}

Klinisyenler hastalarına mümkün olan en iyi bakımı verebilmek için bilimsel araştırmaları ve güncel bilgileri takip ederek bunları kendi klinik tecrübeleri ve hastaların durumu ve öncelikleriyle sentezlemelidir. Klinik kararların kanıta dayalı yaklaşım temelinde alınmasında uygulama rehberleri yol göstericidir.

\section{KAYNAKLAR}

1) Stetler CB, Brunell M, Giuliano KK, Morsi D, Prince L, Newell-Stokes V. Evidence-based practice and the role of nursing leadership. J Nurs Adm 1998;28(7-8):45-53.

2) Estabrooks CA. Will evidence-based nursing practice make practice perfect? CJNR 1999;30(4):273-94.

3) Youngblut J, Brooten D. Evidence-based nursing practice: Why is it important?AACN Clin Issues 2001;12(4):468-76.
4) Cook DJ, Greengold NL, Ellrodt AG. The relation between systematic reviews and practice guidelines. Ann Intern Med 1997;127:210-6.

5) Clinical Practice Guidelines.In: Field MJ, Lohr KN, eds. 1st ed. Washington DC: National Academy Press 1990:1-166.

6) Twaddle S. Clinical practice guidelines. Singapore Med J 2005;46(12):681-6.

7) Garrnck D, Hendricks AM, Brennan TA. Can practice guidelines reduce the number and costs of malpractice claims? JAMA 1991;266:2856-60.

8) Hadorn DC, McCormick K, Diokno A. An annotated algorithm approach to clinical guideline development. JAMA 1992;267:3311-4.

9) Hyams AL BJ, Lipsitz SR, Shapiro DW, Brennan TA. Practice guidelines and malpractice litigation: a two-way street. Ann Intern Med 1995;122:450-5.

10) Van Amringe $M$, Shannon TE. Awareness, assimilation, andadoption: the challenge of effective dissemination and the first AHCPRsponsored guidelines. It Comm Q Rev Bull 1992;18:397-404.

11) Boston MA. Clinical Practice Guidelines.Washington: Management Decision and Research Center 1998:1-36.

12) IDF Clinical Guidelines Task Force. Global guideline for Type 2 diabetes. Brussels: International Diabetes Federation 2005.

13) Kelly JT. The interface of clinical paths and practice parameters.In: Spath PL, ed. Clinical paths: tools for outcomes management. Chicago: American Hospital Publishing 1994:45-56.

14) Hoffmann PA. Critical path method: an important tool for coordinating clinical care. Jt Comm J Qual Improv 1993;19:235-46.

15) Kellie SE, Kelly JT. Medicare peer review organization preprocedure review criteria: an analysis of criteria for three procedures JAMA1991(265):1265-70.

16) Buzgan T, Tumay Ş, Buyurgan V, Bayazıt $Y$. Meningokoksik menenjit saha rehberi. Ankara: TC Sağlık Bakanlığı Temel Sağlık Hizmetleri Genel Müdürlüğü 2005:10-6. 